Most ethicists distinguish forgoing or withdrawing life-sustaining therapies from physicians hastening death (assisted suicide or euthanasia). It is debatable whether a family would regard suicide (whether physician-assisted or not) as less devastating than a planned withdrawal from a ventilator.

Initially addressing the patient's perceptions that ALS could only be a "long-lasting agony," presenting the current interventions and strategies that improve quality of life as well as potentially extend meaningful life, may have prevented the chaos and distress that ensued. Fear of future suffering as well as concerns about burdening family are the most prominent reasons for interest in hastening death. The desire to remain autonomous and in control is also a major motivation. Physician-assisted death is legal in only a few jurisdictions; concerns that it might be viewed as "convenient" may be a motivating factor to those who oppose it.

Dr. Jablecki's thoughts and suggestions are appreciated. The positive reframing of the statement about physicians remaining available to their patients with ALS is welcome. In no way do we feel that appropriate transfer of care, in situations as you describe, represents abandonment. In fact, standard of care would suggest that all patients with ALS be offered care at a specialty multidisciplinary clinic; referral to an ALS clinic does not represent abandonment, but the original physician should not assume the other physician or clinic has taken over until the patient is actually seen or enrolled.

Thank you for drawing our attention to your article about predicting survival. Patients and families often wish to have discussions about prognosis and expectations of timing of interventions. We feel that these are appropriate when tailored to the individual and should occur only after enough information has been gathered over several clinical assessments so as to be meaningful. What we decry is the all-too-familiar statement (or variation thereof) given to patients and families at the time of diagnosis that "average survival is 2 years (or 18 months or 3 years)." In what other neurologic condition is the information so baldly conveyed? The progression of disability and timing of decisions about respiratory and nutritional interventions is highly variable. At the time of diagnosis we honestly do not know what the course will be, so we feel that it is inappropriate to convey these population-based statistics as part of breaking the news.

Disclosures: See original article for full disclosure list.

Correspondence to: wendy.johnston@ualberta.ca

1. Johnston WS, Hoskins K, McCluskey L. Amyotrophic lateral sclerosis: ethical challenges. Neurology 2011;76:S1-S5.

2. Jablecki CK, Berry C, Leach J. Survival prediction in ALS. Muscle Nerve 1989;12:833-841.

\title{
The evaluation of polyneuropathies
}

Jaume Revuelto-Rey, MD, Juan J. Egea-Guerrero, MD, Francisco Murillo-Cabezas, Virgen del Rocio University Hospital, Seville, Spain: We enjoyed reading the Burns et al. ${ }^{1}$ article about the evaluation of polyneuropathies but missed the discussion of critical illness polyneuropathy.

It is the primary axonal degeneration of motor and sensory fibers that can lead to degeneration of muscle fibers. This occurs in critically ill patients, including those with systemic inflammatory response syndrome, sepsis with multiple organ dysfunction syndrome, hyperglycemia, or in those requiring muscle relaxants, corticosteroids, or parenteral nutrition. This may occur in up to $80 \%$ of critically ill patients, usually in the form of quadriplegia or quadriparesis, with abolished tendon reflexes and no pathologic changes in the CSF. ${ }^{2}$

The neurophysiologic study shows primary axonal degeneration of motor and sensory fibers with preservation of conduction velocity, normal distal latency, and potential fall of 
motor response. Moreover, it is important to demonstrate denervation in the muscles as an expression of the sharpness of the process, as evidenced by the EMG onset of fibrillation potentials and positive waves. $^{3}$

There no effective treatment for this condition because identifying the problem and establishing early physiotherapy are the most appropriate measures for its management. However, identification of risk factors should prompt a close metabolic control of septic patients, especially avoiding hyperglycemia and hyperosmolarity. In addition, patients should avoid the use of muscle relaxants. ${ }^{4}$

In serious cases, persistence of immobility and quality of life deterioration at 2 years after diagnosis was reported in almost all patients. Prolonged intensive care unit stay, longer duration of sepsis, and weight loss are the 3 conditions associated with poorer recovery. ${ }^{5}$

Considering the incidence and clinical implications, critical illness polyneuropathy should be included in the differential diagnosis of polyneuropathies.

Disclosures: The authors report no disclosures.

Correspondence to: drjau@hotmail.com

Authors Respond: Ted M. Burns, MD, University of Virginia, Charlottesville; Michelle L. Mauermann, MD, Mayo Clinic, Rochester, MN: We thank the authors of the correspondence for their summary of critical illness polyneuropathy, which acts as a worthy addition to our article.

Disclosures: See original article for full disclosure list.

Correspondence to: tmb8r@virginia.edu

1. Burns TM, Mauermann ML. The evaluation of polyneuropathies. Neurology 2011;76:S6-S13.

2. Amaya-Villar R, Garnacho-Montero J, Rincon-Ferrari MD. Neuromuscular abnormalities in critical illness. Med Intens 2009;33:123-133.

3. Khan J, Harrison TB, Rich MM, Moss M. Early development of critical illness myopathy and neuropathy in patients with severe sepsis. Neurology 2006;67:1421-1425.

4. Mesejo A, Perez-Sancho E, Moreno E. Clinical consequences of neuromuscular impairments in critically ill patients. Nutr Hosp 2006;21:104-113.

5. Garnacho-Montero J, Madrazo-Osuna J, Garcia Garmendia JL, et al. Critical illness polyneuropathy: Risk factors and clinical consequences: a cohort study in septic patients. Intens Care Med 2001;27: $1288-1296$ 


\title{
Neurology ${ }^{\circ}$ Clinical Practice
}

The evaluation of polyneuropathies

\author{
Jaume Revuelto-Rey, Ted M. Burns, Juan J. Egea-Guerrero, et al. \\ Neurol Clin Pract 2011;1;3-4 \\ DOI 10.1212/01.CPJ.0000410052.07169.b7
}

This information is current as of December 1, 2011

$\begin{array}{ll}\begin{array}{l}\text { Updated Information \& } \\ \text { Services }\end{array} & \begin{array}{l}\text { including high resolution figures, can be found at: } \\ \text { http://cp.neurology.org/content/1/1/3.full.html }\end{array} \\ \text { References } & \begin{array}{l}\text { This article cites } 5 \text { articles, } 2 \text { of which you can access for free at: } \\ \text { http://cp.neurology.org/content/1/1/3.full.html\#\#ref-list-1 }\end{array} \\ \text { Permissions \& Licensing } & \begin{array}{l}\text { Information about reproducing this article in parts (figures,tables) or in } \\ \text { its entirety can be found online at: } \\ \text { http://cp.neurology.org/misc/about.xhtml\#permissions }\end{array} \\ \text { Reprints } & \begin{array}{l}\text { Information about ordering reprints can be found online: } \\ \text { http://cp.neurology.org/misc/addir.xhtml\#reprintsus }\end{array}\end{array}$

Neurol Clin Pract is an official journal of the American Academy of Neurology. Published continuously since 2011, it is now a bimonthly with 6 issues per year. Copyright Copyright $₫ 2011$ by AAN Enterprises, Inc.. All rights reserved. Print ISSN: 2163-0402. Online ISSN: 2163-0933.

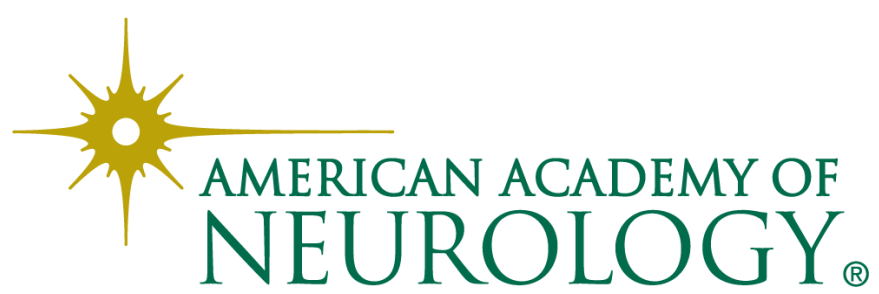

